\title{
GREAT BLUE HERONS AND RACOONS AT NICOLLE FLATS
}

DALE G. HJERTAAS, Wildlife Branch, Saskatchewan Tourism and Renewable Resources, 3211 Albert Street, Regina, Saskatchewan. S4S 5W6

\section{Introduction}

Great Blue Herons have nested at Nicolle Flats, on the banks of the Qu'Appelle River, since at least 1883. Mr. Doug Nicolle, who still farms in the area, reports that the colony was active when his grandfather, Charles Nicolle, homesteaded in the area that year. The colony has been occupied each year to the present.

The first published account of the colony was 65 nests in $1970 .{ }^{12}$ In 1975 there were 70 nests, over half of which contained young ${ }^{3}$ but this was reduced to 52 platforms, some dilapidated, of which only 16 had young in 1976 (pers. comm. David Hatch). I located 23 active nests during my first visit to the colony on 8 May 1978. Disappointingly, when I returned on 18 June all had failed.

During 1978 and 1979 I, with other members of the Qu'Appelle Fish and Wildlife team, were developing Nicolle Flats as a wildlife area. Maintenance of the heron colony was an important objective for the area. I therefore began searching for the cause of the population decline since 1970, the total reproductive failure in 1978 and a way to halt the population decline.

I soon learned that the Great Blue Heron population along the entire Qu'Appelle Valley had declined since the 1960's. Vermeer and Anweiler reported four active colonies totalling 121 nests along the Qu'Appelle Valley in $1970 .^{12}$ They also reported 3 colonies which had been abandoned in the Qu'Appelle in the 1950's and 60's. I resurveyed the Qu'Appelle Valley by aircraft on 16 May 1979 but could find only the Nicolle Flats colony, now reduced to 7 nests, an 8 nest colony near Round Lake, and a lone nest near Craven for a total of 16 nests. This is only $13 \%$ of the nesting population present 9 years earlier!

One of three alternate hypotheses, human disturbance, predation by Racoons, or infertility due to pesticide poisoning, appeared most likely to explain the heron population decline at Nicolle Flats and elsewhere in the Qu'Appelle.

\section{Disturbance}

Human disturbance seems unlikely due to the isolation of the Nicolle Flats colony. The colony was only disturbed in one year, 1973 or 1974 , when people drove into the area, crossed a beaver dam, and shot at least 20 young herons out of the nests. There were approximately 60 active heron nests at that time (personal communication Doug Nicolle). This isolated incident, although unfortunate, does not explain the continuing decline of the heron colony.

\section{Pesticides}

Residues of some pesticides produce thin shelled eggs which often break during incubation and fail to hatch. Faber et al investigated the effects of organochlorines and mercury on herons in California. ${ }^{2}$ Egg shell thickness of California Great Blue Herons has declined significantly since 1947 , Table 1 also shows that there was a significant difference in thickness between shells which broke during incubation and those which hatched successfully. 
Table 1. GREAT BLUE HERON EGG SHELL THICKNESS FROM CALIFORNIA AND NICOLLE FLATS

Category of Egg

Pre 1947 specimens $^{2}$

Hatched California shells ${ }^{2}$ 1969 and 1970

Broken California shells ${ }^{2}$ 1969 and 1970

Nicolle Flats, 1978

$\begin{array}{cc}\begin{array}{c}\text { Mean } \\ \text { Thickness }(\mathrm{mm})\end{array} & \begin{array}{c}\text { Confidence } \\ \text { Limits }\end{array} \\ 0.396 & 0.390-0.402 \\ 0.365 & 0.354-0.376\end{array}$

0.326

$0.310-0.346$

0.369

$0.360-0.378$

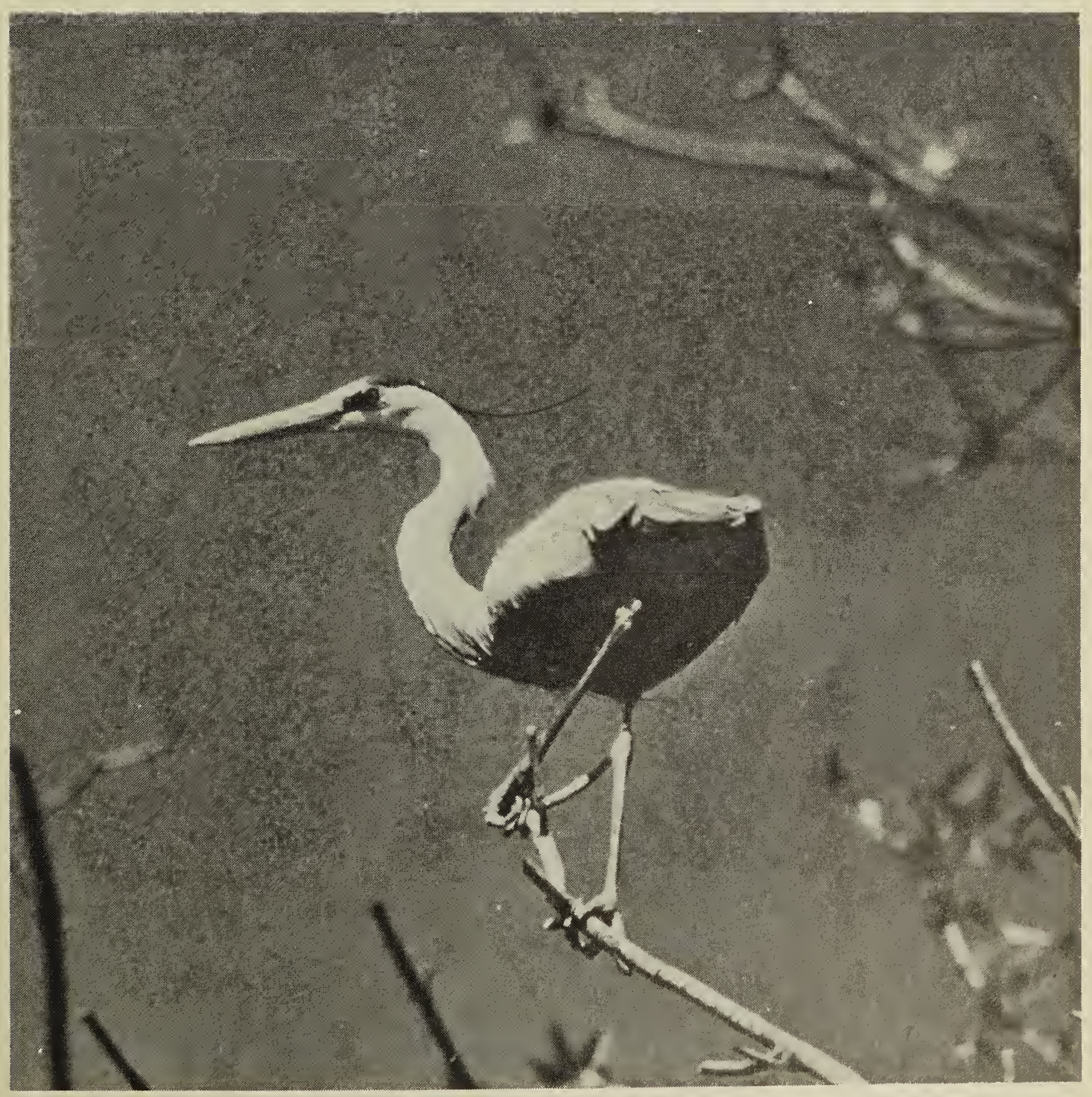


I collected egg shells from the failed Nicolle Flats colony in 1978. Egg membranes were removed and thickness of 99 shell fragments determined with Mitutoyo dial callipers with gradations to .05 millimeters. I then compared shell thickness at Nicolle Flats with those from California. Confidence limits wree calculated for the sample. Non-overlap of confidence limits indicated a significant difference. ${ }^{2}$

Table 1 shows that shells at Nicolle Flats have the same thickness as those in nests hatched successfully in California in 1969 and 1970. Nicolle Flats shells are significantly thinner than prepesticide era shells from California, but significantly thicker than those shells which broke during incubation. Egg shell thinning due to pesticides may therefore be occurring at Nicolle Flats, but is not severe enough to be responsible for the colony failure.
Some poisons, such as mercury, do not cause egg shell thinning. I was unwilling to sacrifice any eggs or birds for analysis so could not test for presence of these toxins.

\section{Predation by Racoons}

Hatch \& Lieffers suggested that predation by Racoons may be reducing nest success at Nicolle Flats and commented that predation of heron nests by Racoons was known in Manitoba. ${ }^{4}$ In California several Racoons learned to climb the redwood trees in which Great Egrets and Great Blue Herons nested at Audubon Canyon Ranch. Nest losses were heavy until the Racoons were trapped and relocated. ${ }^{9}$ Lopinot actually observed a Racoon climb to a nest 50 feet above ground and feed on heron remains. ${ }^{7}$ Observed or suspected Racoon predation on heron and egret nests has also been reported in Texas, Georgia and North Carolina. ${ }^{10} 111$

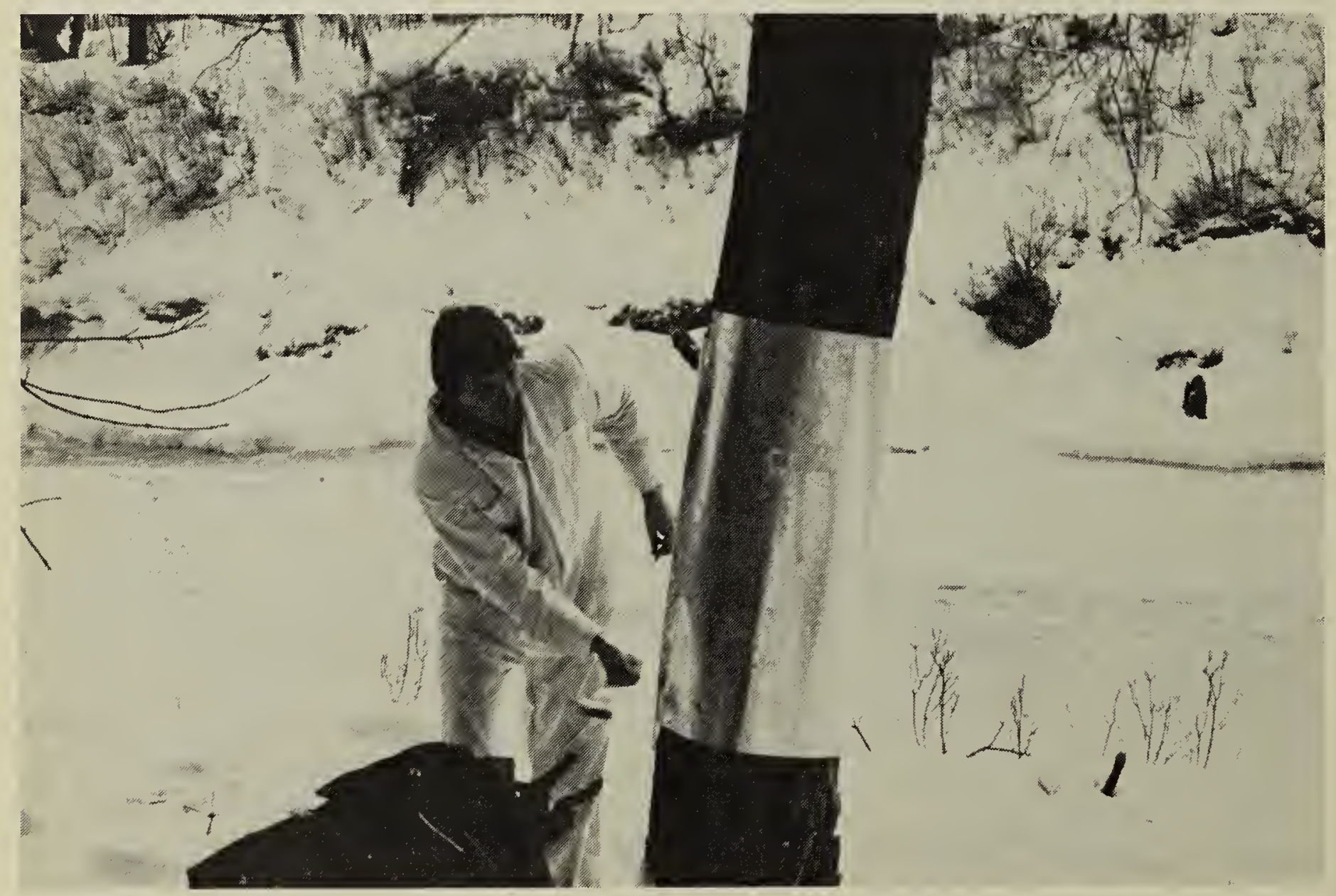

Lindsay setting up Racoon guards at Nicolle Flats heronry. 
In most areas heronries are in locations which reduce the risk from mammalian predators. Florida heronries are usually located over water or on other areas not frequented by Racoons. ${ }^{6}$ Often alligators live under heron colonies, scavenging waste which might attract Racoons and effectively deterring Racoons from visiting the colony. Nests in other areas are also often in over water or island situations. The colony destruction by Racoons in North Carolina was due to low water levels which allowed Racoons to reach a normally isolated colony.

In Saskatchewan the absence of tree climbing mammalian predators has allowed Great Blue Herons to prosper even though isolated island and over water nest sites are limited. Racoons are a recent addition to the Saskatchewan fauna, the first recorded specimen having been taken in 1919. Racoons first colonized the Qu'Appelle and Souris River Valleys. They gradually increased in numbers and extended their range north and west, but the average annual fur harvest in Saskatchewan did not exceed 100 pelts until the 1960's. ${ }^{5}$ By 1975 Racoons were abundant in the Qu'Appelle Valley east of Buffalo Pound Lake. ${ }^{8}$ The Racoon population increase in the Qu'Appelle thus appears to be coincident with the Great Blue Heron population decline.

Presence of a high Racoon population at Nicolle Flats was confirmed in 1978 by the abundance of feces and tracks. Even though analysis of feces failed to show evidence of nest robbing I began testing of a "racoon guard" for nest trees in 1978.

Staff at the Saskatoon Forestry Farm Park obligingly placed a six foot maple post, 9 inches in diameter, in the cage of their four Racoons. The Racoons were fed on a platform at the top of this post for two weeks. On 11 October, I placed a "racoon guard" on the post. This "racoon guard" consisted of a 36 inich sheet of stainless steèl wrapped around the post from 5 inches above ground to 37 inches above ground. The metal was overlapped and the joint nailed every 3 or 4 inches to ensure there were no cracks to provide toe holds. During the next two days the Racoons were unable to climb the post to reach their food on the platforms and the experiment was terminated. The "racoon guard" worked!

In March 1979 Lindsay Surbey and I placed "racoon guards" on 21 nest trees in the Nicolle Flats colony. We also cut off low branches or stumps which might offer a bypass route into the trees. The "racoon guards" were left loose enough to allow for some future tree growth.

Due to my underestimate of the amount of sheet metal required, several trees at the eastern edge of the colony, which had not been occupied in 1978, were left unguarded. During the winter of 1980 wildlife staff placed additional "racoon guards" to protect all trees in the Nicolle Flats colony. In addition all guards were painted a dull brown as the shiny metal guards had been clearly visible through the trees in 1979 and may have disturbed the herons.

I surveyed the colony by aircraft in May of 1979, 1980 and 1981 flying at sufficient altitude that no herons flushed. All herons observed sitting or standing on nests were counted. This may produce a slight over estimate as mates perched on adjacent old nests would be counted as nest attempts.

I checked nest success at the colony each year from the ground. I was easily able to identify nests with young by presence of "white wash" below the nest. I counted the number of young visible in each nest, but did not climb trees to ensure the counts were accurate. Counts of young are therefore minimum estimates of production. 
Table 2. GREAT BLUE HERONS NESTING AT NICOLLE FLATS 1978 - 1981

No Racoon Guards

Nests Initiated

Nests Successful

Young Produced

Young/Successful Nest

With Racoon Guards

Nests Initiated

Nests Successful

Young Produced

Young/Successful Nest
1981

0

0

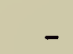

$\begin{array}{cccc}1978 & 1979 & 1980 & 1981 \\ 23 & 6 & 0 & 0 \\ 0 & 0 & - & - \\ 0 & 0 & - & - \\ 0 & 0 & - & - \\ & & & \\ - & 1 & 8 & 15 \\ - & 1 & 7 & 12 \\ - & 4 & 16 & 28 \\ - & 4 & 2.3 & 2.3 .\end{array}$

$\begin{array}{cccc}1978 & 1979 & 1980 & 1981 \\ 23 & 6 & 0 & 0 \\ 0 & 0 & - & - \\ 0 & 0 & - & - \\ 0 & 0 & - & - \\ & & & \\ - & 1 & 8 & 15 \\ - & 1 & 7 & 12 \\ - & 4 & 16 & 28 \\ - & 4 & 2.3 & 2.3 .\end{array}$

Young/Successtur Nest

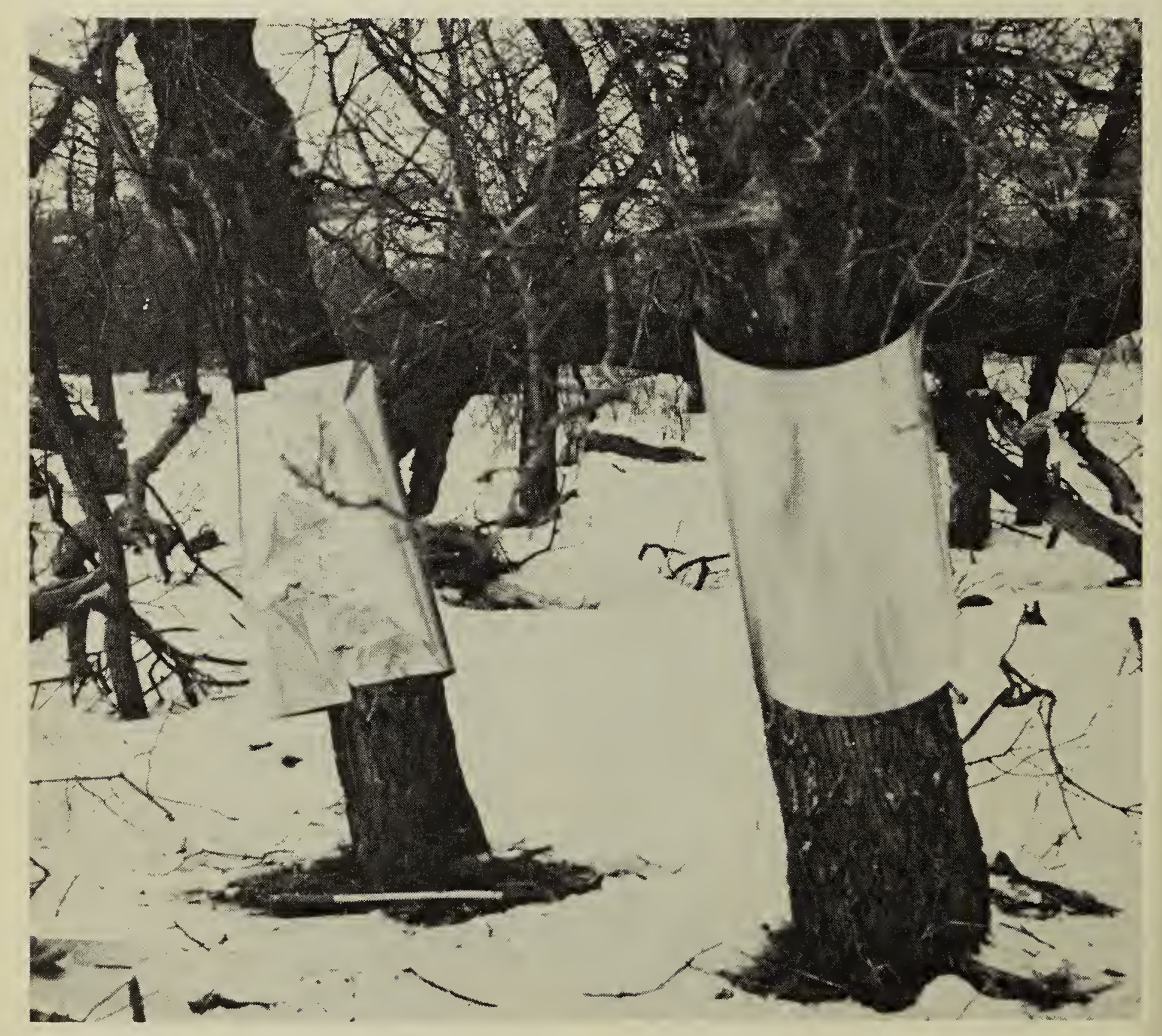

Racoon guards at Nicolle Flats heronry. 
Table 2 shows that during 1978 , 1979, 1980 and 1981 herons made 29 nest attempts in unguarded trees, none of which were successful. During the same period 20 of 24 nest attempts in trees with "racoon guards" were successful and produced a minimum of 48 young.

\section{Discussion}

This difference in nest success definitely implicates predation as a cause of the decline in the Nicolle Flats heron colony. Racoons are implicated as the only likely tree climbing predator in the area. In addition the coincident increase in Racoon populations and decline in herons throughout the Qu'Appelle suggests that predation by Racoons is responsible for the Great Blue Heron population decline throughout the Qu'Appelle Valley. This decline is continuing. Failure of the Round Lake colony in 1980 leaves the Nicolle Flats colony as the only known Great Blue Heron colony in the Qu'Appelle. "Racoon guards" were erected at the Round Lake colony in the spring of 1981 but I was unable to inspect the colony to determine if the herons returned.

The decline of the heron population in the Qu'Appelle indicates that similar declines may occur as the Racoon population increases in other areas. Naturalists should try to check the success of heron colonies annually, especially in the south eastern part of the province where Racoon populations are highest.

\section{Acknowledgement}

I wish to acknowledge the assistance of Paule Hjertaas and G. W. Pepper, who reviewed the manuscript, and Lindsay Surbey, Dave Arneson, Lindy Peters and Phil Haughian, who erected the racoon guards.
'CHAMBERLAIN, B. R. 1951. The Nesting Season: Southern Atlantic Coast Region. Audubon Field Notes 5 (5): 285-6

${ }^{2}$ FABER, RAYMOND et al. 1972. Organo Chlorines and Mercury in Common Egrets and Great Blue Herons. Environ. Pollution (3): 111-122

${ }^{3}$ HATCH, D. \& V. LIEFFERS. 1977. Status of the Birds of the Qu'Appelle Basin. Wildlife Technical Report 77-32. Sask. Dept. of Tourism \& Renewable Resources, Saskatoon, Sask.

${ }^{4} \mathrm{HATCH}$, D. \& V. LIEFFERS. 1977. A Wildlife Management Proposal for the Nicolle Flats Addition to Buffalo Pound Provincial Park. Wildlife Technical Report 7717. Sask. Dept. of Tourism \& Renewable Resources, Saskatoon, Sask.

${ }^{5}$ HOUSTON, C. STUART \& MARY 1. HOUSTON. 1973. A History of Racoons in Saskatchewan. Blue Jay 31(2): 103-4

${ }^{6}$ JENNI, DONALD A. 1969. A Study of the Ecology of Four Species of Herons During the Breeding Season at Lake Alice, Alachua County, Florida. Eco Mono. 39(3): 245-270

${ }^{7}$ LOPINOT, ALVIN C. 1951. Racoon Predation on the Great Blue Heron. Auk 68: 235

${ }^{8}$ SHERRATT, D. and D. HATCH. 1977. Qu'Appelle Mammalian Inventory. Wildlife Technical Report 77-37. Sask. Tourism \& Renewable Resources, Saskatoon, Sask.

'STALLCUP, RICH and JON WINTER. 1975. The Nesting Season: June 1 - July 31 , 1975. Middle Pacific Coast Region. American Birds 29(5): 1025-29

${ }^{10}$ TAYLOR, REESE \& EDWIN D. MICHAEL. 1971. Predation on an Inland Heronry in Eastern Texas. Wilson Bulletin 83: $172-$ 77

"TEAL, JOHN M. 1965. Nesting Success of Egrets and Herons in Georgia. The Wilson Bulletin 77: 257-63

${ }^{2}$ VERMEER, KEES \& GARY G. ANWEILER. 1970. Great Blue Heron Colonies in Saskatchewan in 1970. Blue Jay 28(4): 158-161 